\title{
Distribution and characterization of estrogen receptor $G$ protein-coupled receptor 30 in the rat central nervous system
}

\author{
Eugen Brailoiu, Siok L Dun, G Cristina Brailoiu, Keisuke Mizuo, Larry A Sklar ${ }^{1}$, Tudor I Oprea ${ }^{2}$, \\ Eric R Prossnitz ${ }^{3}$ and Nae J Dun \\ Department of Pharmacology, Temple University School of Medicine, 3420 North Broad Street, Philadelphia, Pennsylvania 19140, USA \\ ${ }^{1}$ Department of Pathology, ${ }^{2}$ Division of Biocomputing, Department of Biochemistry and Molecular Biology and ${ }^{3}$ Department of Cell Biology and Physiology, \\ University of New Mexico School of Medicine, Albuquerque, New Mexico 87131, USA \\ (Requests for offprints should be addressed to E Brailoiu; Email: ebrailou@temple.edu)
}

\begin{abstract}
The G protein-coupled receptor 30 (GPR 30) has been identified as the non-genomic estrogen receptor, and G-1, the specific ligand for GPR30. With the use of a polyclonal antiserum directed against the human C-terminus of GPR 30, immunohistochemical studies revealed GPR30-immunoreactivity (irGPR30) in the brain of adult male and nonpregnant female rats. A high density of irGPR 30 was noted in the Islands of Calleja and striatum. In the hypothalamus, irGPR30 was detected in the paraventricular nucleus and supraoptic nucleus. The anterior and posterior pituitary contained numerous irGPR30 cells and terminal-like endings. Cells in the hippocampal formation as well as the substantia nigra were irGPR 30. In the brainstem, irGPR30 cells were noted in the area postrema, nucleus of the solitary tract, and dorsal motor nucleus of the vagus; a cluster of cells
\end{abstract}

were prominently labeled in the nucleus ambiguus. Tissue sections processed with pre-immune serum showed no irGPR 30, affirming the specificity of the antiserum. G-1 $(100 \mathrm{nM})$ caused a large increase of intracellular calcium concentrations $\left[\mathrm{Ca}^{2+}\right]_{\mathrm{i}}$ in dissociated and cultured rat hypothalamic neurons, as assessed by microfluorometric Fura- 2 imaging. The calcium response to a second application of G-1 showed a marked homologous desensitization. Our result shows a high expression of irGPR 30 in the hypothalamic-pituitary axis, hippocampal formation, and brainstem autonomic nuclei; and the activation of GPR 30 by G-1 is associated with a mobilization of calcium in dissociated and cultured rat hypothalamic neurons.

Journal of Endocrinology (2007) 193, 311-321

\section{Introduction}

The steroid hormone estrogen produces a variety of cell responses, many of which can be attributed to the activation of two known estrogen receptors $\alpha$ and $\beta$ (ER $\alpha$ and ER $\beta)$, which function as transcription factors (Jensen \& DeSombre 1973, Mosselman et al. 1996). However, a number of cell responses are induced in seconds to minutes following estrogen stimulation, for example, nitric oxide generation, calcium mobilization, and activation of tyrosine kinases (Morley et al. 1992, Brubaker \& Gay 1999, Karpuzoglu et al. 2006). For this reason, the existence of non-genomic ERs mediating rapid cell signaling has been proposed in a number of studies (Lagrange et al. 1997, Pietras \& Szego 1977, Singh et al. 2000, Toran-Allerand et al. 2002, Morales et al. 2003, Qiu et al. 2003).

Two groups independently proposed that the G proteincoupled receptor (GPR 30), is the non-genomic ER (Revankar et al. 2005, Thomas et al. 2005). A high-affinity, displaceable, single binding site specific for estrogen was detected respectively in plasma membranes of SKBR 3 breast cancer cells that express GPR 30 but lack nuclear ERs, and in
COS7 cells transfected with GPR30 (Revankar et al. 2005, Thomas et al. 2005). As GPR30 is expressed in cell lines in these studies (Revankar et al. 2005, Thomas et al. 2005), the distribution of GPR30 in the brain has not been investigated. An earlier study demonstrates that COS7 cells transfected with GPR30 responded to estrogen with a large influx of $\mathrm{Ca}^{2+}$ (Revankar et al. 2005). The present study was undertaken to determine the distribution of GPR30 in the central nervous system of adult rats of either sex, and to characterize the calcium response of native GPR30 in dissociated and cultured rat hypothalamic neurons in response to the GPR30-specific ligand G-1 (Bologa et al. 2006).

\section{Materials and Methods}

\section{Immunohistochemistry}

Adult male and female Sprague-Dawley rats, weighing 225-250 g (Ace Animals Inc., Boyertown, PA, USA), were used in this study. Animal protocols were reviewed and approved by the Institution Animal Care and Use Committee. 
Animals were anesthetized with urethane $(1 \cdot 2 \mathrm{~g} / \mathrm{kg}$, i.p.) and intracardially perfused with $0 \cdot 1 \mathrm{M}$ PBS followed by $4 \%$ paraformaldehyde $/ 0 \cdot 2 \%$ picric acid in PBS. Brains and pituitary glands were removed, post-fixed for $2 \mathrm{~h}$, and stored in 30\% sucrose/PBS solution overnight.

In single-staining, tissues were processed for GPR30immunoreactivity (irGPR30) by the avidin-biotin complex procedure (Brailoiu et al. 2005). Tissues were first treated with $3 \% \mathrm{H}_{2} \mathrm{O}_{2}$ to quench endogenous peroxidase, washed several times, blocked with $10 \%$ normal goat serum, and incubated in GPR30 antiserum (1:1000 dilution). GPR30 antiserum was a rabbit polyclonal antibody directed against the human C-terminus GPR30 (CAVIPDSTEQSDVRFSSAV; Revankar et al. 2005). The specificity of GPR 30 antiserum has been previously confirmed (Revankar et al. 2005). After thorough rinsing, sections were incubated in biotinylated anti-rabbit IgG (1:150 dilution, Vector Laboratories, Burlingame, CA, USA) for $2 \mathrm{~h}$, rinsed with PBS, and incubated in avidinbiotin complex solution for $1 \mathrm{~h}$ (1:100 dilution, Vector Laboratories). Following several washes in Tris-buffered saline, sections were incubated in $0.05 \%$ diaminobenzidine/ $0 \cdot 001 \% \mathrm{H}_{2} \mathrm{O}_{2}$ solution and washed for at least $2 \mathrm{~h}$ with Trisbuffered saline. Sections were mounted on slides with $0 \cdot 25 \%$ gel alcohol, air-dried, dehydrated with absolute alcohol followed by xylene, and coverslipped with Permount. For control experiments, sections were processed with preimmune serum in the place of GPR30 antiserum.

In the case of double-labeling experiments, hypothalamic and medullary sections were first blocked with normal goat serum $(1: 10$ in PBS, $0.5 \%$ BSA, $0.4 \%$ Triton $X-100)$ and then incubated with GPR30 antiserum (1:500 dilution). Following several washes with PBS, sections were incubated with biotinylated anti-rabbit IgG (1:50, Vector Laboratories), washed with PBS, and incubated with fluorescein isothiocyanate (FITC). After rinsing with PBS, the hypothalamic sections were incubated with either oxytocin (OT) antibody (1:1000, a monoclonal antibody from Chemicon, Tamecula, CA, USA) or vasopressin (VP) antiserum (1:1500, a guinea pig polyclonal antibody from Chemicon); medullary sections were incubated with choline acetyltransferase (ChAT) antiserum (1:1000; a guinea pig polyclonal antibody from Bachem Bio Sciences Inc., King of Prussia, PA, USA) for $48 \mathrm{~h}$ in a cold room. In the case of double labeling with the neuronal marker neuron-specific enolase, cultured hypothalamic neurons were fixed in $4 \%$ paraformaldehyde $/ 0 \cdot 2 \%$ picric acid, blocked with $10 \%$ normal goat serum, and incubated with GPR30 antiserum (1:500 dilution). They were washed with PBS and incubated with biotinylated antirabbit $\mathrm{IgG}$, followed by avidin FITC. After rinsing with PBS, the cells were blocked with normal donkey serum and incubated with neuron-specific enolase antiserum (1:150, a mouse monoclonal antibody from Chemicon). Tissues and cells were incubated in Avidin Texas Red conjugated to appropriate secondary antibodies, washed with PBS, and mounted in Citifluor and coverslipped. Sections and cells were examined under a confocal scanning laser microscope
(Leica Microsystems Inc., Exton, PA, USA) with excitatio$\mathrm{n} / \mathrm{emission}$ wavelengths set to $488 / 520 \mathrm{~nm}$ for FITC and $543 / 620 \mathrm{~nm}$ for Texas Red in the sequential mode.

\section{Neuronal cell culture}

Cells were isolated from the hypothalamus of postnatal 1- to 3 -day-old rats by enzymatic digestion with $0.5 \mathrm{mg}$ papain/100 mg tissue (Dun et al. 2006). Cells were plated at a density of $10^{3} / \mathrm{mm}^{2}$ in a Neurobasal-A medium, supplemented with $10 \%$ fetal calf serum, $2 \mathrm{mM}$ glutamine, 100 units $/ \mathrm{ml}$ penicillin, and $100 \mu \mathrm{g} / \mathrm{ml}$ streptomycin (Invitrogen), and maintained at $37^{\circ} \mathrm{C}$ in a humidified atmosphere with $5 \% \mathrm{CO}_{2}$. Glial cell growth was inhibited by the mitotic inhibitor cytosine $\beta$-arabino furanoside (1 $\mathrm{MM}$; Sigma). Neurons were cultured for 5 days. Cells were transferred to a medium without fetal serum $12 \mathrm{~h}$ prior to $\mathrm{Ca}^{2+}$ measurements.

\section{Cytosolic $\mathrm{Ca}^{2+}$ concentrations}

Cytosolic $\mathrm{Ca}^{2+}$ measurements were performed as described previously (Brailoiu et al. 2006). Cells were incubated with $5 \mu \mathrm{M}$ Fura-2 AM (Molecular Probes, Eugene, OR, USA) in Hanks' balanced salt solution (HBSS) at room temperature for $45 \mathrm{~min}$ in the dark, washed thrice with dye-free buffer, and then incubated for another $45 \mathrm{~min}$ to allow for complete de-esterification of the dye. Coverslips were subsequently mounted in a custom-designed bath on the stage of an Eclipse TE 2000-U Nikon inverted microscope equipped with a Roper Scientific CCD camera (Optical Apparatus Co., Ardmore, PA, USA). Cells were routinely superfused with HBSS at a flow rate of $1 \mathrm{ml} / \mathrm{min}$. Fura-2 fluorescence $($ emission $=510 \mathrm{~nm})$, following alternate excitation at 340 and $380 \mathrm{~nm}$, was acquired at a frequency of $0.33 \mathrm{~Hz}$. Images were acquired and analyzed using Metafluor software. For $\mathrm{Ca}^{2+}$-free experiments, HBSS without $\mathrm{Ca}^{2+}$ supplemented with $2.5 \mathrm{mM}$ EGTA was used.

\section{Chemicals}

G-1 was a gift from Chemical Diversity Inc. (San Diego, CA, USA).

\section{Statistical analysis}

In calcium measurement experiments, statistical significance between groups was tested using one-way ANOVA followed by Bonferroni test, $P<0.05$ being considered significantly different.

\section{Results}

\section{Immunohistochemistry}

Examination of sections prepared from four female and five male rats revealed a similar pattern of distribution of irGPR 30 
in the brain and pituitary. Results described below are derived from male rats unless stated otherwise. The nomenclature follows that used in Paxinos \& Watson (1998).

\section{Forebrain}

A high density of irGPR 30 was detected in the Islands of Calleja (ICj), major island (ICjM), ventral pallidum (VP), and olfactory tubercle ( $\mathrm{Tu}$ ); a lesser density of irGPR30 was present in the nucleus of vertical limb diagonal band (VDB; Fig. 1A-D). A high density of irGPR30 was detected in the rostro-caudal extent of lateral globus pallidus (Fig. 1E and F). In the thalamus, irGPR30 was detected in the reticular thalamic nucleus (Fig. 1E) and medial habenular nucleus (not shown).

With respect to the hypothalamus, cells in the paraventricular nucleus (PVN), supraoptic nucleus (SO), and accessory neurosecretory nuclei (acc) were strongly labeled (Fig. 2A-C). Within the PVN, irGPR30 was identified mostly in the lateral magnocellular part (PaLM), medial parvicellular part (PaMP), ventral part $(\mathrm{PaV})$, dorsal cap $(\mathrm{PaDC})$, and less in the anterior and posterior parvicellular parts (Fig. 2B). Few cells in the suprachiasmatic nucleus, retrochiasmatic nucleus, and periventricular hypothalamic nucleus were immunoreactive (Fig. 2A). The arcuate nucleus showed a moderate number of irGPR30 cells (not shown).

Incubation with pre-immune serum resulted in little or no irGPR30 in hypothalamic sections; an example is shown in Fig. 2D.

\section{Pituitary gland}

With respect to the pituitary gland, the anterior pituitary contained a large number of immunoreactive cells (Fig. 2E); numerous terminal-like endings were irGPR30 in the posterior pituitary (Fig. 2F).

\section{Hippocampus}

Cells in the hippocampal formation including CA1, CA2, CA3 regions and dentate gyrus (DG) were irGPR30 (Fig. 3A and $\mathrm{B})$.

\section{Midbrain and medulla oblongata}

At the level of pons, a high concentration of irGPR30 was seen in the substantia nigra reticular and compact parts (SNR, SNC; Fig. 3C and D). In the medulla, positively labeled cells were noted in the area postrema (AP), dorsal motor nucleus of the vagus (10), nucleus of the solitary tract (Sol), and hypoglossal nucleus (12, Fig. 4A and B). A cluster of irGPR30 cells was conspicuously present in the nucleus ambiguus (Amb; Fig. 4C-D). In addition, irGPR30 cells were distributed sparsely throughout the reticular formation (Fig. 4A).

\section{Co-expression}

Double-labeling of the hypothalamic sections with GPR30antiserum and OT or VP antiserum revealed that $\sim 40$ and $32 \%$ irGPR 30 cells were OT-positive, and about 60 and $70 \%$ irGPR30 cells were VP-positive, in the hypothalamic paraventricular and $\mathrm{SOs}$ respectively (Fig. 5A-D). In the medulla oblongata, nearly all irGPR 30 cells in the Amb, dorsal motor nucleus of the vagus, and hypoglossal nucleus were ChAT-positive (Fig. 5E and F). With respect to cultured hypothalamic neurons, irGPR30 was co-localized with neuron-specific enolase (Fig. 6A and B), affirming that irGPR 30 was expressed in cultured neurons.

\section{Intracellular $\left[\mathrm{Ca}^{2+}\right]_{i}$}

Administration of G-1 (100 nM), the ligand that selectively activates GPR 30 but not the nuclear ERs ER $\alpha$ and ER $\beta$ (Bologa et al. 2006), induced an increase in $\left[\mathrm{Ca}^{2+}\right]_{\mathrm{i}}$ by $964 \pm$ $8.6 \mathrm{nM}$ in 26 of 109 cells tested; an example is shown in Fig. 7A. The rise of $\left[\mathrm{Ca}^{2+}\right]_{i}$ was rapid and sustained, reaching a plateau in about 3-6 min. In hypothalamic neurons perfused with a $\mathrm{Ca}^{2+}$-free medium, G-1 (100 nM) elevated $\left[\mathrm{Ca}^{2+}\right]_{\mathrm{i}}$ by $58 \pm 2 \cdot 2 \mathrm{nM}(n=6)$; a representative experiment is shown in Fig. 7B.

The next series of experiments was designed to evaluate whether or not GPR30 undergoes desensitization, a feature common to GPRs, by monitoring the $\mathrm{Ca}^{2+}$ responses to two consecutive perfusions of $\mathrm{G}-1$. In those hypothalamic cells responding to the first application of G-1 (100 nM), a second application of G-1 induced an average increase of $\left[\mathrm{Ca}^{2+}\right]_{i}$ of $174 \pm 3.6 \mathrm{nM}$, which was significantly smaller than that elicited by the first G-1 application $(n=10, P<0 \cdot 05)$; a representative experiment is shown in Fig. 8.

\section{Discussion}

The gene that encodes GPR30, also known as CEPR, FEG-1, CMKRL2 or LyGPR, was identified many years prior to the recent proposal that the receptor may serve as the non-genomic ER (Owman et al. 1996, Carmeci et al. 1997, Feng \& Gregor 1997, Kvingedal \& Smeland 1997, Takada et al. 1997, O'Dowd et al. 1998). GPR30 (CEPR or CMKRL2) is a 375 amino acid class-1 GPCR (SwissProt (http://www.expasy.ch/sprot/) primary accession number Q99527 (http://www.expasy.org/uniprot/Q99527)) with highest sequence identity $(<35 \%)$ with members of the chemoattractant receptor family, the $\mathrm{C}-\mathrm{C}$ chemokine 8 receptor, the chemokine receptor CXCR1 ( $\sim 29 \%$ overall identity) and the somatostatin receptor 4 . For this reason, a chemokine was first thought to be the endogenous ligand (O'Dowd et al. 1998). Evidence from an early study (Filardo et al. 2000) and two recent studies (Revankar et al. 2005, Thomas et al. 2005) indicates that GPR30 is an ER, but distinct from the classic ERs, ER $\alpha$ and $\operatorname{ER} \beta$. 

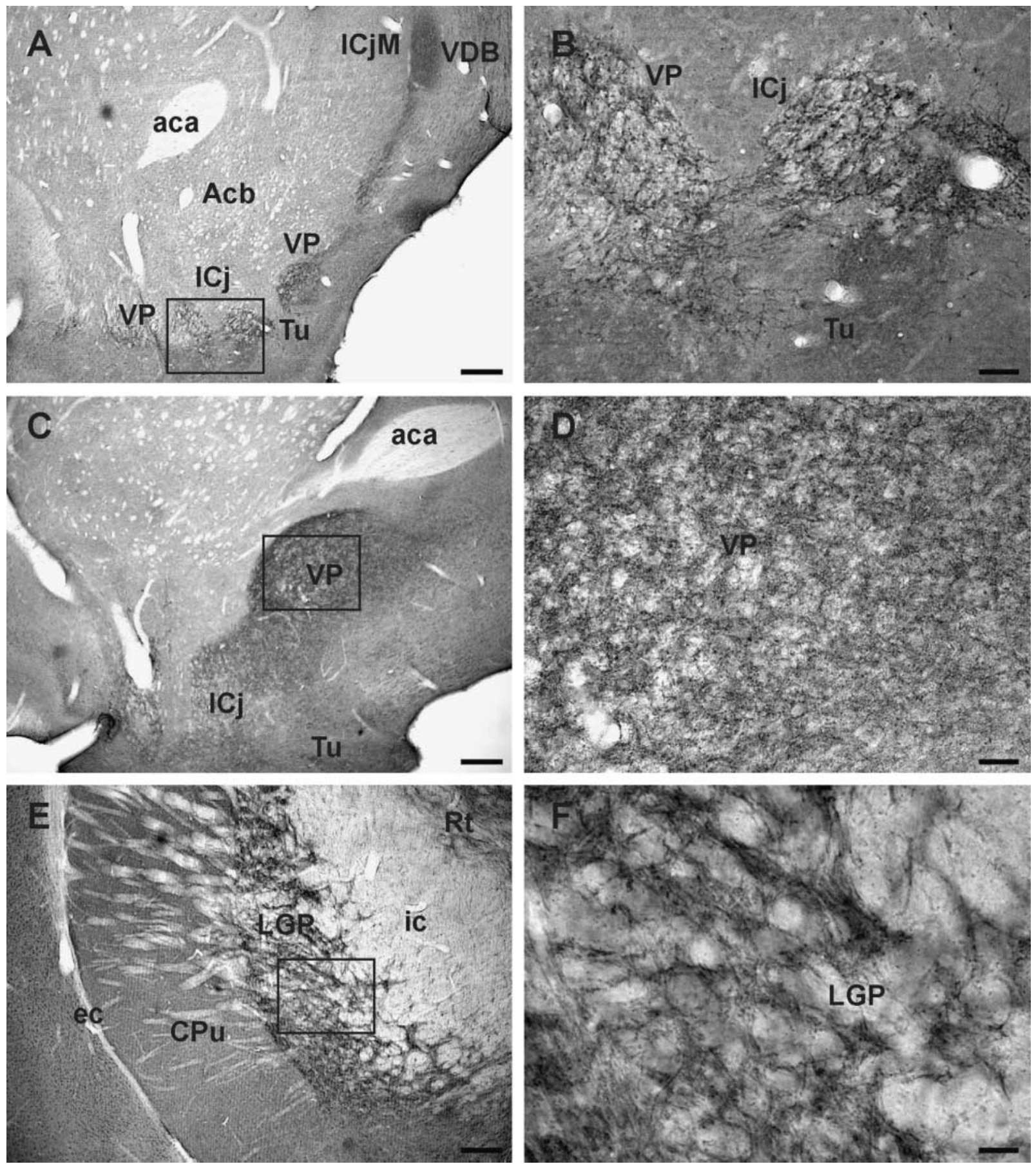

Figure 1 Distribution of irGPR30 in the rat forebrain. (A) A high density of irGPR30 is noted in the Islands of Calleja (ICj), major island (ICjM), ventral pallidum (VP), olfactory tubercle (Tu), nucleus of vertical limb diagonal band (VDB). (B) A higher magnification of the area outlined in A, depicting irGPR30 in the ICj, VP, and Tu. (C) Intense irGPR30 is present in VP. (D) A higher magnification of the area outlined in C, where a high density of irGPR30 is detected in the VP. (E) irGPR30 is detected in the lateral globus pallidus (LGP) and reticular thalamic nucleus (Rt). (F) a higher magnification of the area outlined in $\mathrm{E}$. Abbreviations: aca, anterior commissure anterior part; Acb, accumbens nucleus; $\mathrm{CPu}$, caudate putamen; ec, external capsule; ic, internal capsule. Calibration bar: A, C and E, $250 \mu \mathrm{m} ; \mathrm{B}, \mathrm{D}$ and F, $50 \mu \mathrm{m}$. 

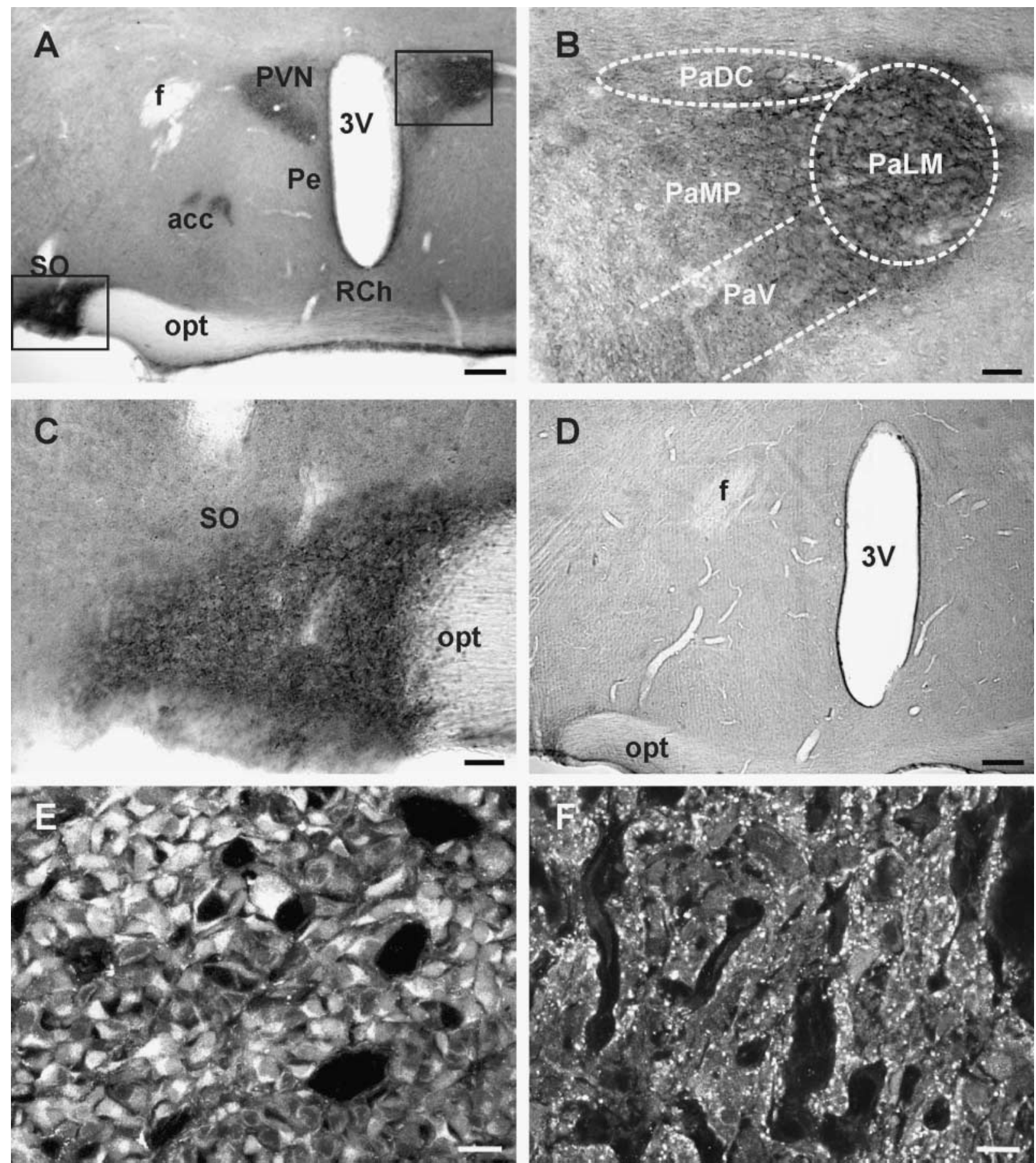

Figure 2 Distribution of irGPR30 in the rat hypothalamus and pituitary. (A) Dense irGPR30 is present in paraventricular hypothalamic nucleus (PVN), accessory neurosecretory nuclei (acc) and supraoptic nucleus (SO). Immunoreactivity is sparse in periventricular hypothalamic nucleus (Pe) and retrochiasmatic nucleus (RCh). (B) A higher magnification of PVN, where irGPR30 is seen in the lateral magnocellular part (PaLM), medial parvicellular part (PaMP), ventral part (PaV), and dorsal cap (PaDC). (C) A higher magnification of SO where dense irGPR30 is detected. (D) A hypothalamic section processed with pre-immune serum; immunoreactivity is not detected in this section. (E) irGPR30 cells are detected in the anterior pituitary. (F) Punctate-like elements, presumably nerve terminals, are observed in the posterior pituitary. E and F are immunofluorescent images. Abbreviations: $\mathrm{f}$, fornix; $3 \mathrm{~V}$, 3rd ventricle; opt, optic tract. Calibration bar: A and D, $250 \mu \mathrm{m} ; \mathrm{B}$ and $\mathrm{C}, 50 \mu \mathrm{m} ; \mathrm{E}$ and $\mathrm{F}, 20 \mu \mathrm{m}$. 

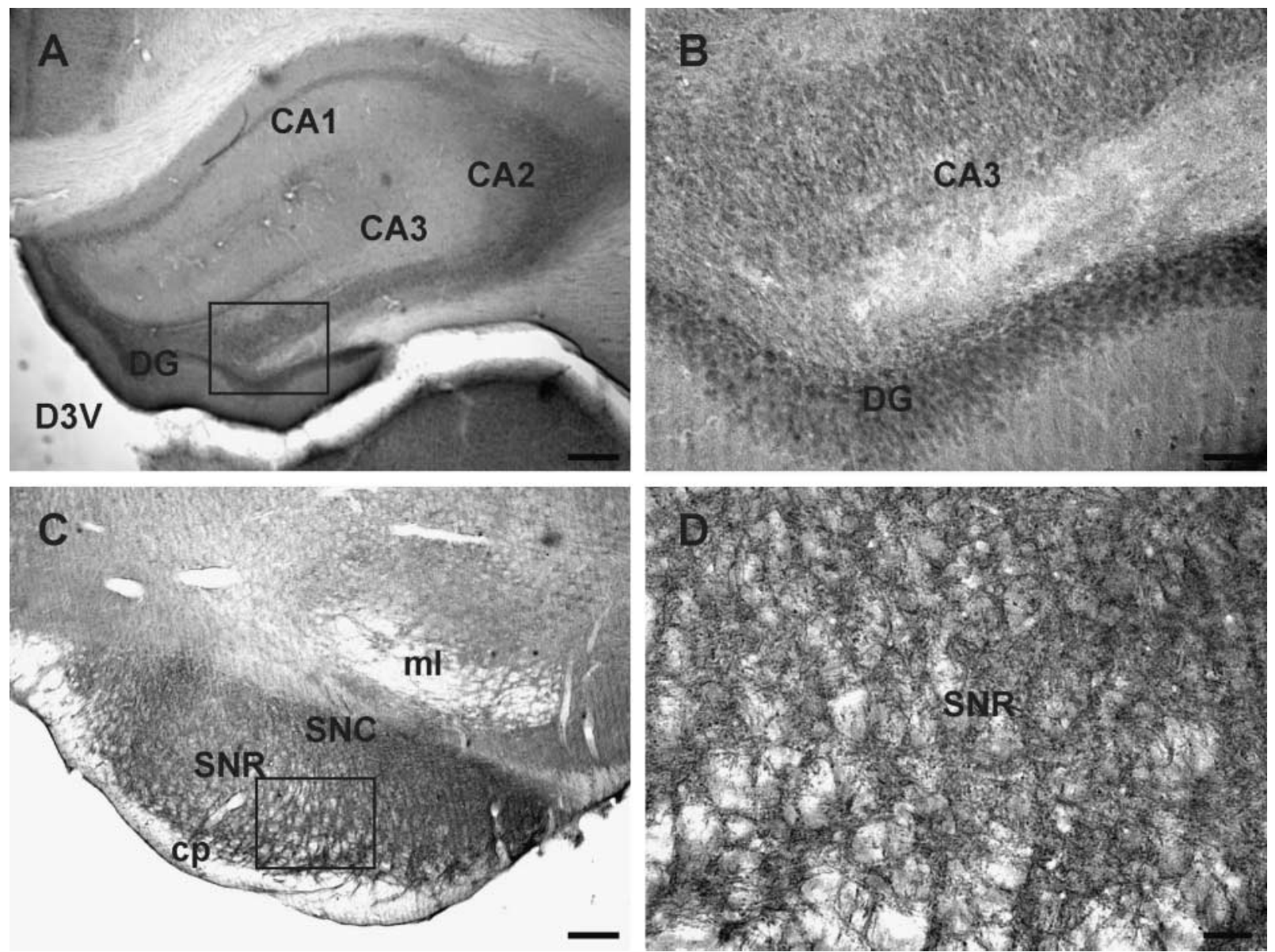

Figure 3 Distribution of irGPR30 in the hippocampus and substantia nigra. (A) Hippocampal formation expressing irGPR30 at the level of dentate gyrus (DG) and CA1, CA2, and CA3 fields. (B) A higher magnification of the area outlined in A, showing irGPR30 in DG and CA3. (C) irGPR30 is observed in substantia nigra reticular part (SNR) and compact part (SNC). (D) A higher magnification of the area outlined in C. Abbreviations: $\mathrm{cp}$, cerebral peduncle; D3V, dorsal $3^{\text {rd }}$ ventricle; $\mathrm{ml}$, medial lemniscus. Calibration bar: A and C, $250 \mu \mathrm{m}$; B and D, $50 \mu \mathrm{m}$.

Using an antiserum directed against the human C-terminus GPR 30, irGPR30 was detected in the Tu, hypothalamus, hippocampal formation, substantia nigra, medulla oblongata, and pituitary. As tissues processed with pre-immune serum, instead of GPR 30 antiserum, resulted in no positive labeling, the irGPR30 appears to be specific. Further, the expression pattern of GPR30 (or CMKRL2 or CEPR) mRNA in human brain tissues (Owman et al. 1996, Feng \& Gregor 1997, O'Dowd et al. 1998) is similar to the receptor distribution profile observed here in the rat brain. For example, GPR 30 mRNA is highly expressed in the Tu, hippocampus, supraoptic, paraventricular, arcuate, and suprachiasmatic nuclei; the signal is less abundant in the cortex and caudate nucleus (O'Dowd et al. 1998). CEPR mRNA is highly expressed in the caudate nucleus, hippocampus, substantia nigra, subthalamic nucleus, thalamus, hypothalamus, medulla oblongata, and spinal cord (Feng \& Gregor 1997).

Our results show that the pattern of irGPR 30 expression is similar in the adult male and female rat brain. This is in agreement with the report in which a gender difference relative to the distribution of $\operatorname{ER} \alpha$ and $\operatorname{ER} \beta$ is not observed in the rat brain (Laflamme et al. 1998). Several areas, such as the ICj and $\mathrm{Tu}$, express ER $\alpha$ and ER $\beta$ (Laflamme et al. 1998) as well as irGPR 30. Other areas, for example, the substantia nigra and AP express irGPR 30 and ER $\alpha$ mRNA, whereas the paraventricular hypothalamic and supraoptic nuclei express irGPR 30 and ER $\beta$ mRNA. Several regions including the amygdala, ventromedial hypothalamic nucleus, and ventral premammillary nucleus, where a strong hybridization signal to $\mathrm{ER} \alpha$ and $\mathrm{ER} \beta$ mRNA is detected (Laflamme et al. 1998), contain little or no irGP30. In spite of partial overlapping with one or the other ER mRNA in different brain regions, our results indicate that the pattern of irGPR30 expression is distinct from that of $E R \alpha$ and $\operatorname{ER} \beta$ in the rat brain.

The co-localization study provides information relative to the phenotype of cells expressing irGPR 30 in the hypothalamus and brainstem. Even if GPR 30 and ER $\beta$ are present in the paraventricular hypothalamic nucleus, they seem to be localized 

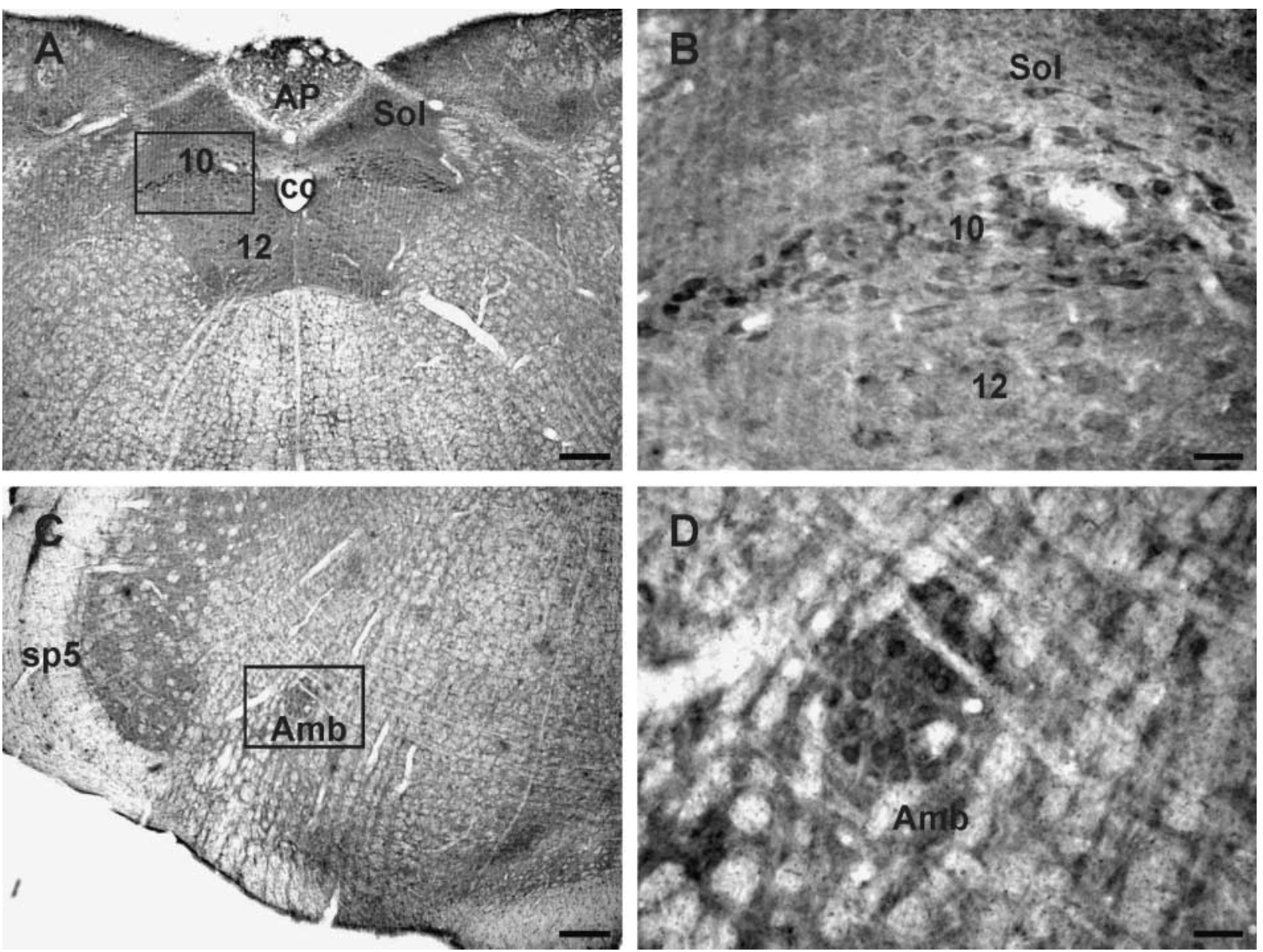

Figure 4 Distribution of irGPR30 in medulla oblongata. (A) irGPR30 cells are present in the dorsal motor nucleus of the vagus (10) and area postrema (AP); few labeled cells are noted in the nucleus of the solitary tract (Sol), and hypoglossal nucleus (12); and scattered cells are seen throughout the reticular formation. (B) A higher magnification of the area outlined in panel A. (C) A group of irGPR30 cells is present in the nucleus ambiguus (Amb). (D) A higher magnification of outlined area shown in C. Abbreviations: cc, central canal; sp5, spinal trigeminal tract. Calibration bar: A and C, $250 \mu \mathrm{m} ; \mathrm{B}$ and D, $50 \mu \mathrm{m}$.

in different cell populations: ER $\beta$ is reported to be highly (60-80\%) expressed in corticotropin releasing factor-positive cells, whereas, the percentage of hypothalamic neurons expressing both ER $\beta$ and VP varies with different studies, ranging from $5 \%$ (Laflamme et al. 1998) to 88-99\% (Hrabovszky et al. 2004). In our study, approximately $60 \%$ of irGPR 30 neurons expressed VP in the paraventricular hypothalamic nucleus. Co-expression of OT and ER $\beta$ is reported to be about $40 \%$ (Laflamme et al. 1998), which is similar to the percentage of co-localization of irGPR30 and OT in the paraventricular hypothalamic nucleus. Estrogens regulate the activity of OT (Akaishi \& Sakuma 1985) and VP neurons (Hartley et al. 2004), and activation of GPR30 could be one of the signaling pathways. With respect to the nucleus Amb, irGPR30 neurons are ChAT-positive, thus are cholinergic.

There is evidence that GPR30 is localized to the endoplasmic reticulum of COS7 cells transfected with the receptor (Revankar et al. 2005). In another study, GPR30 is shown to be localized to the plasma membrane of human breast cancer cells (Thomas et al. 2005). A more recent study shows that GPR 30 is localized to the plasma membrane of rat hippocampal CA2 neurons, and in GPR30-transfected HeLa cells the receptor is translocated to the cytoplasm upon agonist stimulation (Funakoshi et al. 2006). In the case of our immunohistochemical study, irGPR 30 seems to be distributed throughout the cytoplasm in some of the neurons; e.g. dorsal motor nucleus of the vagus (DMNV; Fig. 4B) and Amb (Figs 4D and 5E). On the other hand, irGPR30 may be affiliated with plasma membranes of hypothalamic and hippocampal neurons (Figs 2B, C and 3B). Immunofluorescent staining clearly shows GPR 30 is localized intracellularly; i.e. perinuclear in cells shown in Figs 5A and 6A, and dispersed throughout the cytoplasm in cells illustrated in Fig. 5E. Electron microscopic examination will be needed to resolve the issue of receptor localization. The possibility of a cell type-specific or statedependent localization of GPR30 is intriguing. 

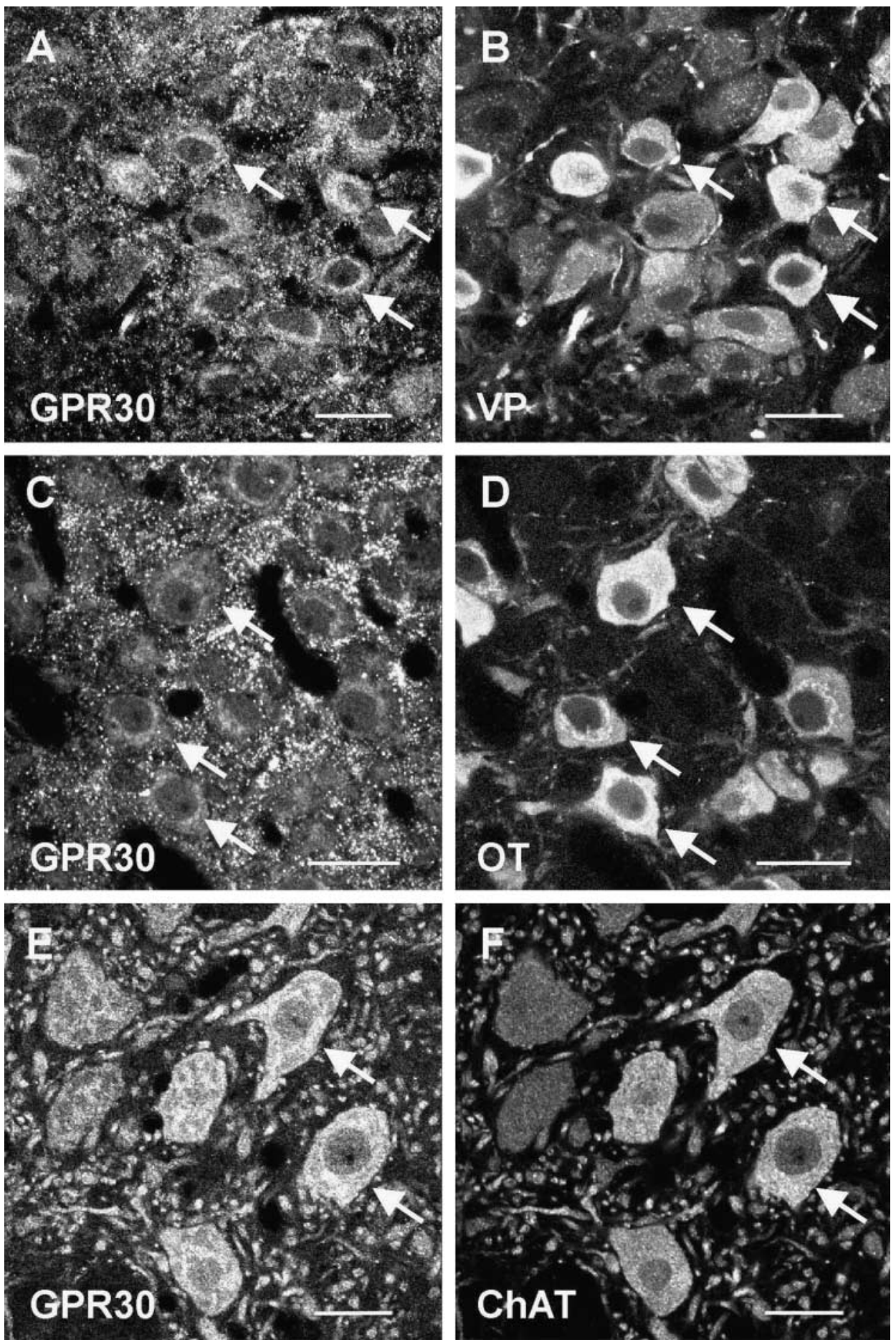

Figure 5 Confocal scanning images of hypothalamic and medullary sections double-labeled with GPR30 antiserum and vasopressin (VP), oxytocin (OT), or choline acetyltransferase (ChAT)-antiserum. (A and B) A hypothalamic section where the supraoptic hypothalamic nucleus is double-labeled with GPR30 antiserum and VP antiserum; some of the cells that express both irGPR30 and VP are indicated by arrows. (C and D) A hypothalamic section where the paraventricular nucleus is double-labeled with GPR30 antiserum and OT antiserum; several cells expressing both irGPR30 and OT are indicated by arrows. (E and F) A brainstem section where nucleus ambiguus is labeled with GPR30 antiserum and ChAT antiserum; cells expressing both irGPR30 and ChAT are indicated by arrows. Calibration bars, $20 \mu \mathrm{m}$. 

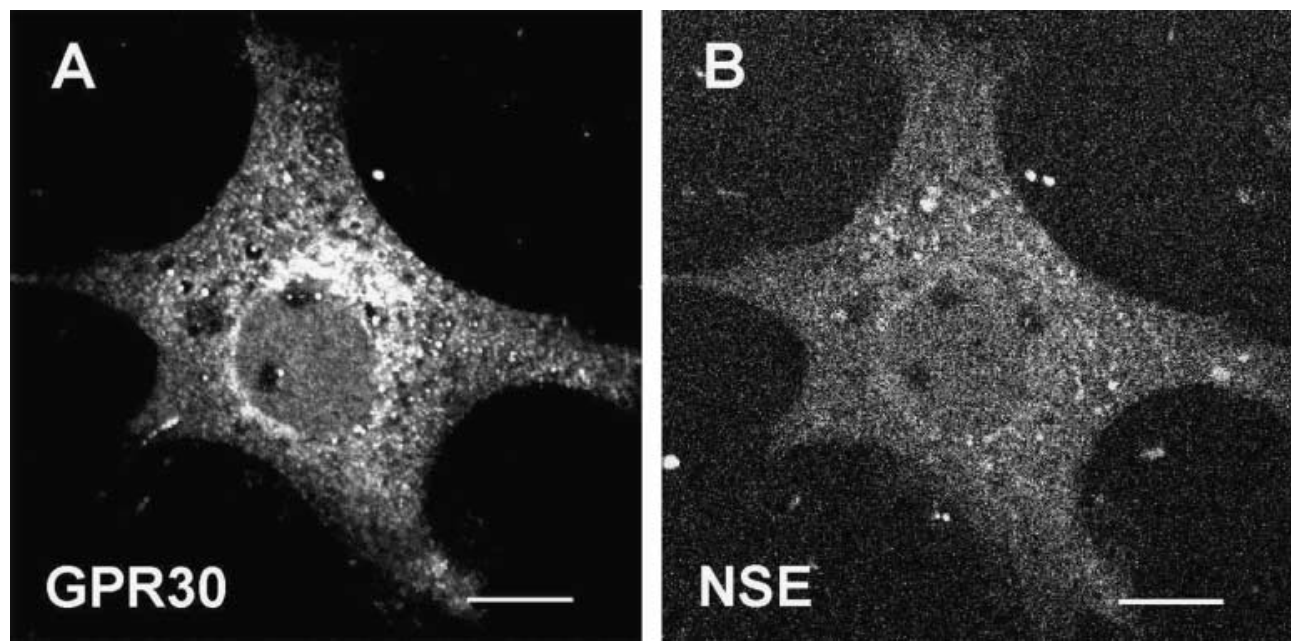

Figure 6 Confocal scanning images of cultured hypothalamic neurons double-labeled with GPR30 and neuronspecific enolase (NSE) antiserum. (A) irGPR30 is distributed throughout the cytoplasm, more intense in the perinuclear region. (B) NSE immunoreactivity is dispersed throughout the cytoplasm. Calibration bar, $10 \mu \mathrm{m}$.

The physiological consequence of activation of GPR30 in a specific neural axis is largely unknown. In addition to its welldocumented hormonal action, estradiol is being considered as a neurotransmitter in the brain (Balthazart \& Ball 2006). Estradiol by intrahippocampal injection enhanced spatial memory in male rats (Packard et al. 1996). Since the expression of ER $\alpha$ and ER $\beta$ mRNA in the hippocampus is limited (Laflamme et al. 1998), GPR 30 may prove to be the major receptor subtype through which estrogen produces its enhancing effect.

In the midbrain, distribution of irGPR30 appears to be restricted to the substantia nigra, compact and reticular parts. $\mathrm{ER} \alpha$ is detected in low levels in the substantia nigra compact part of the rat (Laflamme et al. 1998). Estrogen is reported to have a protective role on dopaminergic neurons in a mouse model (1-methyl-4-phenyl-1,2,3,6-tetrahydropyridine (MPTP)-induced) of Parkinson's disease. However, both the $\operatorname{ER} \alpha$ and $\operatorname{ER} \beta$ appear to be absent in neurons of the substantia nigra of the mouse (Shughrue 2004). Viewed in this context, the neuroprotective effect of estrogen on dopaminergic neurons may be related to activation of GPR30 and independent of nuclear receptors.

With respect to the brainstem, irGPR 30 is detected in the AP, nucleus of the solitary tract, nucleus Amb, and dorsal motor nucleus of the vagus. These nuclei are directly or indirectly associated with autonomic regulation of cardiovascular/gastrointestinal activity. Moreover, estradiol administered directly to the nucleus Amb increased the phenylephrine-induced baroreflex within $5 \mathrm{~min}$ of injection (Saleh et al. 2000). A participation of GPR 30 in this response may be anticipated.

Similar to the COS7 cells transfected with GPR30 (Revankar et al. 2005), G-1 elicited a large increase of $\left[\mathrm{Ca}^{2+}\right]_{\mathrm{i}}$ in dissociated and cultured hypothalamic neurons. Under physiological conditions, circulating estrogens are bound to the carrier proteins, sex hormone-binding globulin, and albumin (Anderson 1974); however, only free estrogen is thought to enter the cell (through diffusion). Unlike the nuclear ERs that activate transcription, protein-bound estrogens mediate non-nuclear receptor signaling (Ramirez et al. 1996, Zheng et al. 1996, Kahn et al. 2002). Estradiol-BSA
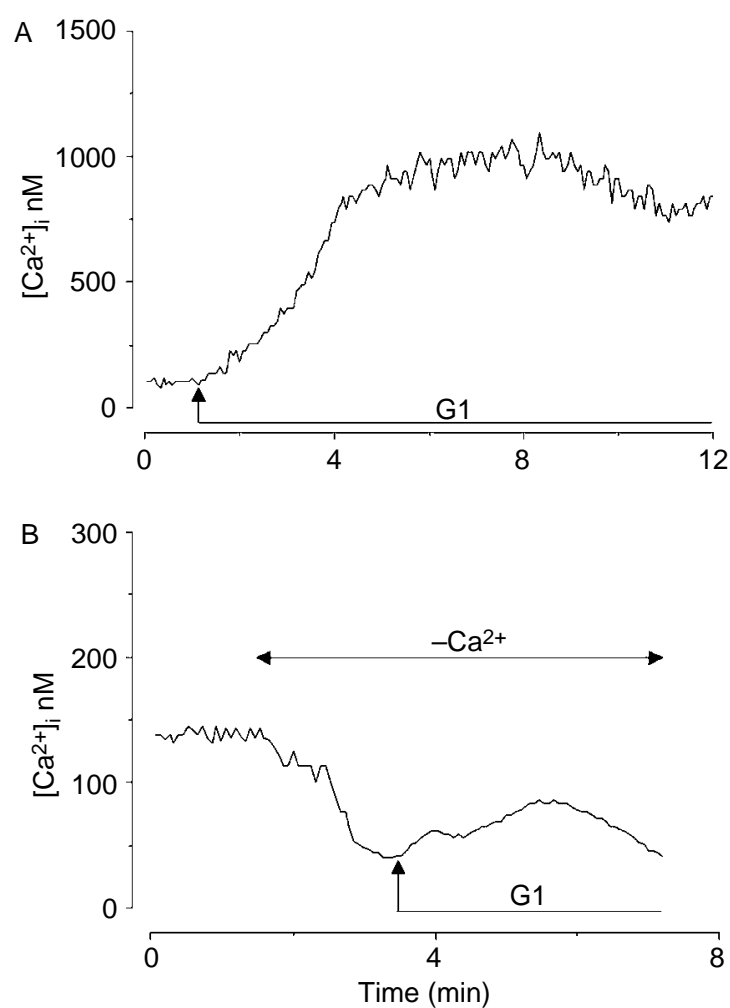

Figure 7 Calcium responses induced by G-1 in hypothalamic neurons. (A) G-1 (100 nM) induced a sustained increase in $\left[\mathrm{Ca}^{2+}\right]_{i}$. (B) G-1 (100 nM) produced a much smaller increase in $\left[\mathrm{Ca}^{2+}\right]_{i}$ in hypothalamic neurons perfused with a $\mathrm{Ca}^{2+}$-free medium. 


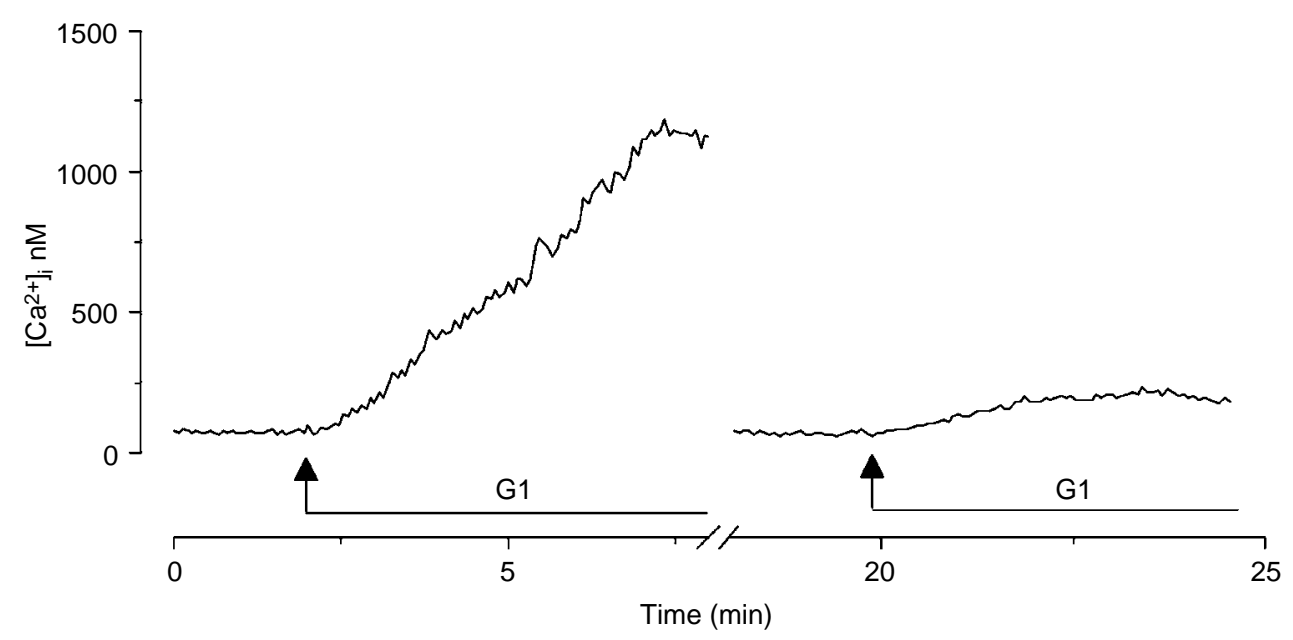

Figure 8 Calcium responses to two consecutive applications of G-1 to a hypothalamic neuron. (A) First application of G-1 (100 nM) produced a large increase in $\left[\mathrm{Ca}^{2+}\right]_{i}$ in a hypothalamic neuron; a second superfusion of G-1 (100 nM) applied immediately after the Ca response had returned to the baseline, produced a much smaller increase in $\left[\mathrm{Ca}^{2+}\right]_{\mathrm{i}}$.

(E2-BSA) has been shown to elevate $\left[\mathrm{Ca}^{2+}\right]_{\mathrm{i}}$ through non-genomic ERs in several cell models; for example, E2BSA elevates $\left[\mathrm{Ca}^{2+}\right]_{\mathrm{i}}$ in gonadotropin-releasing hormone-1 neurons (Temple \& Wray 2005), human granulocytes (Stefano et al. 2000a), and cultured human pre-osteoclastic cells (Fiorelli et al. 1996). Fast calcium mobilization by E2-BSA has also been reported in rat aorta endothelial cells (Rubio-Gayosso et al. 2000), as well as in thoracic and human arterial endothelia (Stefano et al. 2000b). The observation that G-1, the GPR30 selective agonist (Bologa et al. 2006), rapidly elevates $\left[\mathrm{Ca}^{2+}\right]_{\mathrm{i}}$ in hypothalamic cells is consistent with a non-nuclear effect of estrogen. Another novel observation is that the $\mathrm{Ca}^{2+}$ response elicited by a second application of G-1 was significantly smaller as compared with that evoked by the first application, indicating that the non-genomic ER undergoes rapid desensitization. Calcium mobilization and receptor desensitization are two common features of GPRs. Viewed in this context, our observations support the thesis that GPR30 is a GPR.

In a $\mathrm{Ca}^{2+}$-free medium, G-1 causes an elevation of $\left[\mathrm{Ca}^{2+}\right]_{\mathrm{i}}$ with a magnitude much smaller than that elicited in a $\mathrm{Ca}^{2+}$-containing medium, suggesting that activation of GPR30 mobilizes extracellular as well as intracellular $\mathrm{Ca}^{2+}$ stores. Increase of $\left[\mathrm{Ca}^{2+}\right]_{\mathrm{i}}$ in neurons may lead to neurotransmitter release (Brailoiu et al. 2003), modulation of neurite outgrowth (Jacques-Fricke et al. 2006), and hormone secretion (Stojilkovic et al. 2005). Activation of GPR30 by estrogen may influence cell physiology according to the type of cells in question.

\section{Acknowledgements}

This study was supported by NIH grants NS18710 and HL51314 (N J D), CA116662 (E R P) from the Department of Health and Human Services, and by the New Mexico Tobacco Settlement funds ( $\mathrm{T}$ I O). The authors declare that there is no conflict of interest that would prejudice the impartiality of this scientific work.

\section{References}

Akaishi T \& Sakuma Y 1985 Estrogen excites oxytocinergic, but not vasopressinergic cells in the paraventricular nucleus of female rat hypothalamus. Brain Research 335 302-305.

Anderson DC 1974 Sex-hormone-binding globulin. Clinical Endocrinology 3 69-96.

Balthazart J \& Ball GF 2006 Is brain estradiol a hormone or a neurotransmitter? Trends in Neuroscience 29 241-249.

Bologa CG, Revankar CM, Young SM, Edwards BS, Arterburn JB, Kiselyov AS, Parker MA, Tkachenko SE, Savchuck NP, Sklar LA et al. 2006 Virtual and biomolecular screening converge on a selective agonist for GPR30. Nature Chemical Biology 4 207-212.

Brailoiu E, Patel S \& Dun NJ 2003 Modulation of spontaneous transmitter release from the frog neuromuscular junction by interacting intracellular $\mathrm{Ca}^{2+}$ stores: critical role for nicotinic acid-adenine dinucleotide phosphate (NAADP). Biochemical Journal 373 313-318.

Brailoiu GC, Dun SL, Ohsawa M, Yin D, Yang J, Chang JK, Brailoiu E \& Dun NJ 2005 KiSS-1 expression and metastin-like immunoreactivity in the rat brain. Journal of Comparative Neurology 481 314-329.

Brailoiu E, Churamani D, Pandey V, Brailoiu GC, Tuluc F, Patel S \& Dun NJ 2006 Messenger-specific role for nicotinic acid adenine dinucleotide phosphate in neuronal differentiation. Journal of Biological Chemistry 281 15923-15928.

Brubaker KD \& Gay CV 1999 Estrogen stimulates protein tyrosine phosphorylation and Src kinase activity in avian osteoclasts. Journal of Cell Biochemistry 76 206-216.

Carmeci C, Thompson DA, Ring HZ, Francke U \& Weigel RJ 1997 Identification of a gene (GPR 30) with homology to the G-protein-coupled receptor superfamily associated with estrogen receptor expression in breast cancer. Genomics 45 607-617.

Dun SL, Brailoiu E, Wang Y, Brailoiu GC, Liu-Chen LY, Yang J, Chang JK \& Dun NJ 2006 Insulin-like peptide 5: expression in the mouse brain and mobilization of calcium. Endocrinology 47 3243-3248. 
Feng Y \& Gregor P 1997 Cloning of a novel member of the G proteincoupled receptor family related to peptide receptors. Biochemical and Biophysical Research Communications 231 651-654.

Filardo EJ, Quinn JA, Bland KI \& Frackelton AR Jr 2000 Estrogen-induced activation of Erk-1 and Erk-2 requires the G protein-coupled receptor homolog, GPR 30, and occurs via trans-activation of the epidermal growth factor receptor through release of HB-EGF. Molecular Endocrinology 14 1649-1660.

Fiorelli G, Gori F, Frediani U, Franceschelli F, Tanini A, Tosti-Guerra C, Benvenuti S, Gennari L, Becherini L \& Brandi ML 1996 Membrane binding sites and non-genomic effects of estrogen in cultured human preosteoclastic cells. Journal of Steroid Biochemistry and Molecular Biology $\mathbf{5 9}$ 233-240.

Funakoshi T, Yanai A, Shinoda K, Kawano MM \& Mizukami Y 2006 G protein-coupled receptor 30 is an estrogen receptor in the plasma membrane. Biochemical and Biophysical Research Communications 346 904-910.

Hartley DE, Dickson SL \& Forsling ML 2004 Plasma vasopressin concentrations and Fos protein expression in the supraoptic nucleus following osmotic stimulation or hypovolaemia in the ovariectomized rat: effect of oestradiol replacement. Journal of Neuroendocrinology 16 191-197.

Hrabovszky E, Kallo I, Steinhauser A, Merchenthaler I, Coen CW, Petersen SL \& Liposits Z 2004 Estrogen receptor-beta in oxytocin and vasopressin neurons of the rat and human hypothalamus: immunocytochemical and in situ hybridization studies. Journal of Comparative Neurology 473 315-333.

Jacques-Fricke BT, Seow Y, Gottlieb PA, Sachs F \& Gomez TM $2006 \mathrm{Ca}^{2+}$ influx through mechanosensitive channels inhibits neurite outgrowth in opposition to other influx pathways and release from intracellular stores. Journal of Neuroscience 26 5656-5664.

Jensen EV \& DeSombre ER 1973 Estrogen receptor interactions. Science 182 126-134.

Kahn SM, Hryb DJ, Nakhla AM, Romas NA \& Rosner W 2002 Sex hormone-binding globulin is synthesized in target cells. Journal of Endocrinology 175 113-120.

Karpuzoglu E, Fenaux JB, Phillips RA, Lengi AJ, Elvinger F \& Ansar Ahmed S 2006 Estrogen up-regulates inducible nitric oxide synthase, nitric oxide, and cyclooxygenase- 2 in splenocytes activated with T cell stimulants: role of interferon-gamma. Endocrinology 147 662-671.

Kvingedal AM \& Smeland EB 1997 A novel putative G-protein-coupled receptor expressed in lung, heart and lymphoid tissue. FEBS Letters $\mathbf{4 0 7}$ $59-62$.

Laflamme N, Nappi RE, Drolet G, Labrie C \& Rivest S 1998 Expression and neuropeptidergic characterization of estrogen receptors $(\mathrm{ER} \alpha$ and $\operatorname{ER} \beta)$ throughout the rat brain: anatomical evidence of distinct roles of each subtype. Journal of Neurobiology 36 357-378.

Lagrange AH, Rønnekleiv OK \& Kelly MJ 1997 Modulation of G proteincoupled receptors by an estrogen receptor that activates protein kinase A. Molecular Pharmacology 51 606-612.

Morales A, Diaz M, Ropero AB, Nadal A \& Alonso R 2003 Estradiol modulates acetylcholine- induced $\mathrm{Ca}^{2+}$ signals in LHRH-releasing GR 1-7 cells through a membrane binding site. European Journal of Neuroscience $\mathbf{1 8}$ 2505-2514.

Morley P, Whitfield JF, Vanderhyden BC, Tsang BK \& Schwartz JL 1992 A new, nongenomic estrogen action: the rapid release of intracellular calcium. Endocrinology 131 1305-1312.

Mosselman S, Polman J \& Dijkema R 1996 ER $\beta$ identification and characterization of a novel human estrogen receptor. FEBS Letters 392 $49-53$.

O’Dowd BF, Nguyen T, Marchese A, Cheng R, Lynch KR, Heng HH, Kolakowski LF Jr \& George SR 1998 Discovery of three novel G-proteincoupled receptor genes. Genomics 47 310-313.

Owman C, Blay P, Nilsson C \& Lolait SJ 1996 Cloning of human cDNA encoding a novel heptahelix receptor expressed in Burkitt's lymphoma and widely distributed in brain and peripheral tissues. Biochemical and Biophysical Research Communications 228 285-292.

Packard MG, Kohlmaier JR \& Alexander GM 1996 Posttraining intrahippocampal estradiol injections enhance spatial memory in male rats: interaction with cholinergic systems. Behavioral Neuroscience 110 626-632.
Paxinos G \& Watson C 1998 The Rat Brain in Stereotaxic Coordinates. 4th edn, San Diego: Academic Press.

Pietras RJ \& Szego CM 1977 Specific binding sites for oestrogen at the outer surfaces of isolated endometrial cells. Nature 265 69-72.

Qiu J, Bosch MA, Tobias SC, Grandy DK, Scanlan TS, Rønnekleiv OK \& Kelly MJ 2003 Rapid signaling in hypothalamic neurons involves a novel G-protein coupled estrogen receptor that activates protein kinase C. Journal of Neuroscience 23 9529-9540.

Ramirez VD, Zheng J \& Siddique KM 1996 Membrane receptors for estrogen, progesterone, and testosterone in the rat brain: fantasy or reality. Cellular and Molecular Neurobiology 16 175-198.

Revankar CM, Cimino DF, Sklar LA, Arterburn JB \& Prossnitz ER 2005 A transmembrane intracellular estrogen receptor mediates rapid cell signaling. Science 307 1625-1630.

Rubio-Gayosso I, Sierra-Ramirez A, Garcia-Vazquez A, Martinez-Martinez A, Munoz-Garcia O, Morato T \& Ceballos-Reyes G 2000 17Beta-estradiol increases intracellular calcium concentration through a short-term and nongenomic mechanism in rat vascular endothelium in culture. Journal of Cardiovascular Pharmacology 36 196-202.

Saleh MC, Connell BJ \& Saleh TM 2000 Medullary and intrathecal injections of 17beta-estradiol in male rats. Brain Research 867 200-209.

Shughrue PJ 2004 Estrogen attenuates the MPTP-induced loss of dopamine neurons from the mouse SNc despite a lack of estrogen receptors (ERalpha and ERbeta). Experimental Neurology 190 468-477.

Singh M, Satalo G Jr, Guan X, Frail DE \& Toran-Allerand CD 2000 Estrogeninduced activation of the mitogen-activated protein kinase cascade in the cerebral cortex of estrogen receptor- $\alpha$ knock-out mice. Journal of Neuroscience 20 1694-1700.

Stefano GB, Cadet P, Breton C, Goumon Y, Prevot V, Dessaint JP, Beauvillain JC, Roumier AS, Welters I \& Salzet M 2000a Estradiolstimulated nitric oxide release in human granulocytes is dependent on intracellular calcium transients: evidence of a cell surface estrogen receptor. Blood 95 3951-3958.

Stefano GB, Prevot V, Beauvillain JC, Cadet P, Fimiani C, Welters I, Fricchione GL, Breton C, Lassalle P, Salzet M \& Bilfinger TV 2000b Cellsurface estrogen receptors mediate calcium-dependent nitric oxide release in human endothelia. Circulation 101 1594-1597.

Stojilkovic SS, Zemkova H \& Van Goor F 2005 Biophysical basis of pituitary cell type-specific $\mathrm{Ca}^{2+}$ signaling-secretion coupling. Trends in Endocrinology and Metabolism 16 152-159.

Takada Y, Kato C, Kondo S, Korenaga R \& Ando J 1997 Cloning of cDNAs encoding $\mathrm{G}$ protein-coupled receptor expressed in human endothelial cells exposed to fluid shear stress. Biochemical and Biophysical Research Communications 240 737-741.

Temple JL \& Wray S 2005 Bovine serum albumin-estrogen compounds differentially alter gonadotropin-releasing hormone- 1 neuronal activity. Endocrinology 146 558-563.

Thomas P, Pang Y, Filardo EJ \& Dong J 2005 Identity of an estrogen membrane receptor coupled to a $G$ protein in human breast cancer cells. Endocrinology 146 624-632.

Toran-Allerand CD, Guan X, MacLusky NJ, Horvath TL, Diano S, Singh M, Connolly ES Jr, Nethrapalli IS \& Tinnikov AA 2002 ER-X: a novel, plasma membrane-associated, putative estrogen receptor that is regulated during development and after ischemic brain injury. Journal of Neuroscience $\mathbf{2 2}$ 2505-2514.

Zheng J, Ali A \& Ramirez VD 1996 Steroids conjugated to bovine serum albumin as tools to demonstrate specific steroid neuronal membrane binding sites. Journal of Psychiatry and Neuroscience 21 187-197.

Received in final form 21 February 2007

Accepted 28 February 2007

Made available online as an Accepted Preprint

6 March 2007 